\title{
Spatial distribution of Pinus roxburghii Sarg. (Pinaceae) in Rasuwa District of Nepal with the application of Remote Sensing and Geographic Information System
}

\author{
Ila Shrestha \\ Tribhuvan University, Patan Multiple Campus, Lalitpur, Patan Dhoka, Nepal \\ E-mail: shrestha_ila@yahoo.com \\ [Received 02.06.2018; Revised \& accepted 24.06.2018; Published 30.06.2018]
}

\begin{abstract}
This paper develops a spatially detection of Pinus roxburghii Sarg. (Pinaceae) in Rasuwa district with application of Remote Sensing and Geographic Information System. The plant is distributed throughout Nepal at 1100 m - 2100 m, Afghanistan, Himalaya (Kashmir to Bhutan). The analysis has demonstrated that this approach can produce supervise classification results using only SPOT (Satellite Pour I' Observation de la Terre) satellite data in the form of false color composite (FCC) with high resolution of $20 \mathrm{~m}$. The SPOT uses 4 Bands, Red, Green and Infrared Band, among them the panchromatic band has stereo capability. Green band Red band and Near infrared band have classified as Pinus roxburghii. The SPOT satellite has the best resolution amongst the other remote sensing satellites and its products have been selected for this study and collection of ground information.
\end{abstract}

Key words: Rasuwa, Spatial Distribution, SPOT Satellite image, Remote sensing

\section{INTRODUCTION}

Pinus roxburghii Sarg. (Pinaceae) is an evergreen tree of about $30 \mathrm{~m}$ high. Its needle leaves are in threes on each dwarf shoot, $10-20 \mathrm{~cm}$ long. Male cone cylindrical yellowish, female cones brownish, seeds nearly $1 \mathrm{~cm}$ long. The new recruitment of the species is by seeds. It is a common species and locals of the study area collect it by local people for fuel. Roasted seeds are eaten by Tamang people. The resin is applied to hasten healing of cuts and wounds (Manandhar, 2002).

Remote sensing is the science and art of obtaining information about an object, area, or phenomenon through the analysis of data acquired by a device that is not in contact with the object, area or phenomenon under investigation (Lillesand \& Kieffer 1979). Remote sensing technique is a quicker, less expensive and more accurate method of survey compared to the conventional methods. Geographic Information System (GIS) is a tool for resource survey and inventory, which provides a primary source of up to date geographic data (Archibald 1987).

This type of research has been first attempted in Myanmar by Dr. Moe Myint for his $\mathrm{Ph} . \mathrm{D}$. dissertation (1996) is try to establish reliable correlation between species diversity and habitat diversity based on the landscape units extracted from SPOT data on one hand and from intensive field surveys on the other hand. This challenge is applied on specific test sites which are selected using a new concept called Spatially Defined and Spectrally Homogeneous Field Sample (SSS). The same concepts is applied in this research and is the first attempt of this kind in Rasuwa District of Nepal (Shrestha 2016, 2017). The plant species have been studied by Manandhar (2002) and Press et al. (2000) earlier. 


\section{STUDY AREA}

A field study was carried out in the Rasuwa district of Central Nepal lies in Bagmati Zone, between the longitudes $85^{\circ} 10.92^{\prime} \mathrm{E}$ to $85^{\circ} 53.7^{\prime} \mathrm{E}$ and latitudes $27^{\circ} 51.36^{\prime} \mathrm{N}$ to $28^{\circ} 23.1^{\prime} \mathrm{N}$ with altitude ranging from 600 to $7245 \mathrm{~m}$. It is a remote and mountainous and Himalayan area covered with $1544 \mathrm{sq} \mathrm{m}$. More than $80 \%$ land area covered by Langtang National Park. The study area encloses the catchments of two major river systems, one draining west into the Trishuli and other east to the Bhote Koshi. Langtang Lirung (7234 m) is the highest point in the southwest. The lowest point in the study area is approximately $600 \mathrm{~m}$ from the mean sea level. The FCC of the study area is shown in Map - 1.

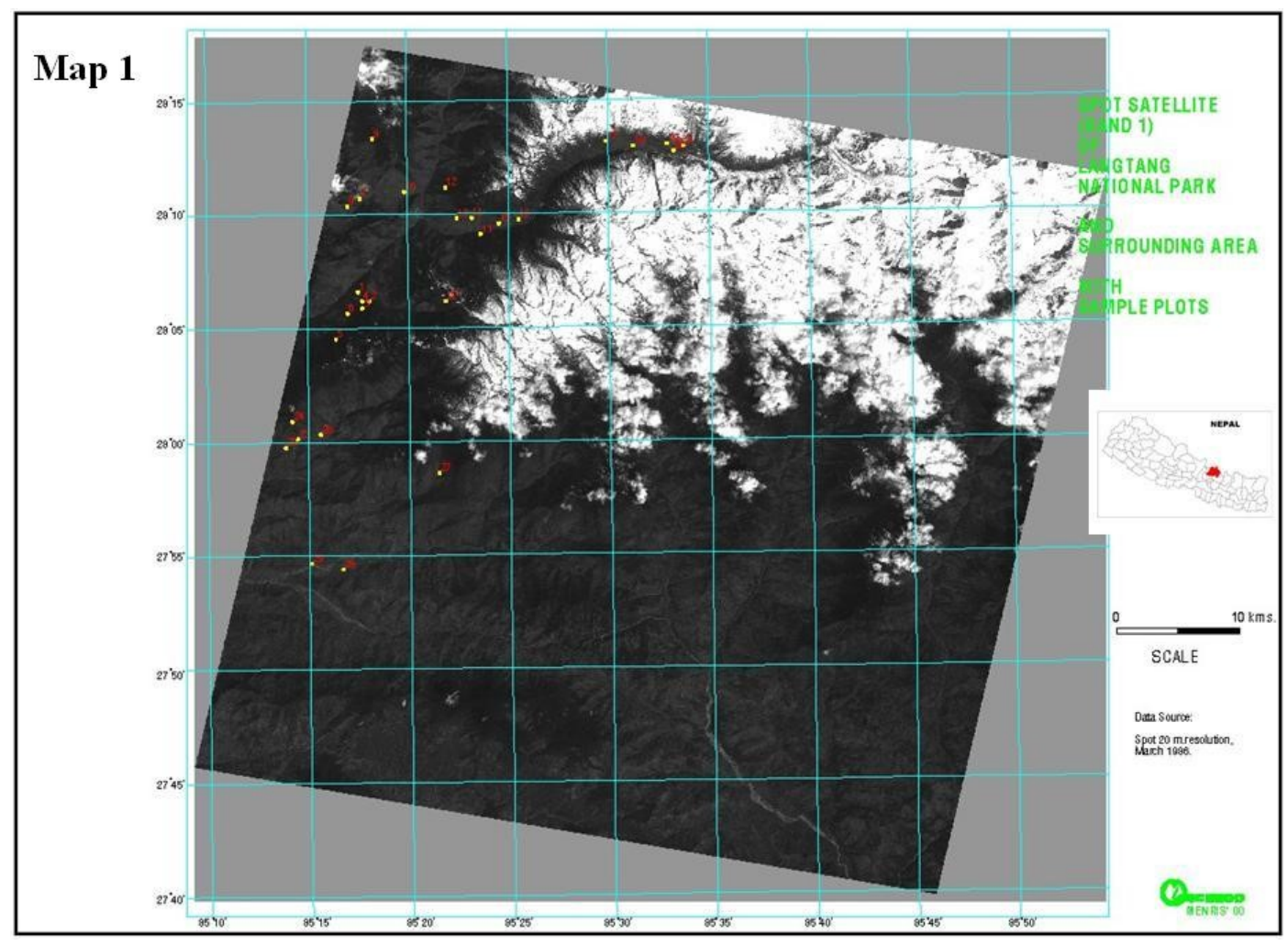

Map - 1. Location of Sample Plots in Rasuwa District

\section{METHODOLOGY}

\section{Work Plan Flow Chart}

The work flow chart for the entire work has been provided in Figure 1 and Figure 2 shows the determination of Quadrate size for ground truthing investigation.

The SPOT satellite data have been used during the research study. The FCC used is having a resolution of $20 \mathrm{~m}$ sq. The SPOT uses spectral bands with the capability to discriminate plants. Satellite has three spectral bands so each pixel of SPOT satellite data consist three-file values. The SPOT uses four bands; among them the panchromatic band has stereo capability. The SPOT satellite has the best resolution amongst the other remote sensing satellites and its products have been selected for this study and collection of ground information. The base map on 1:50,000 scale and 1:25000 scale sheets were prepared from the survey of the topography 


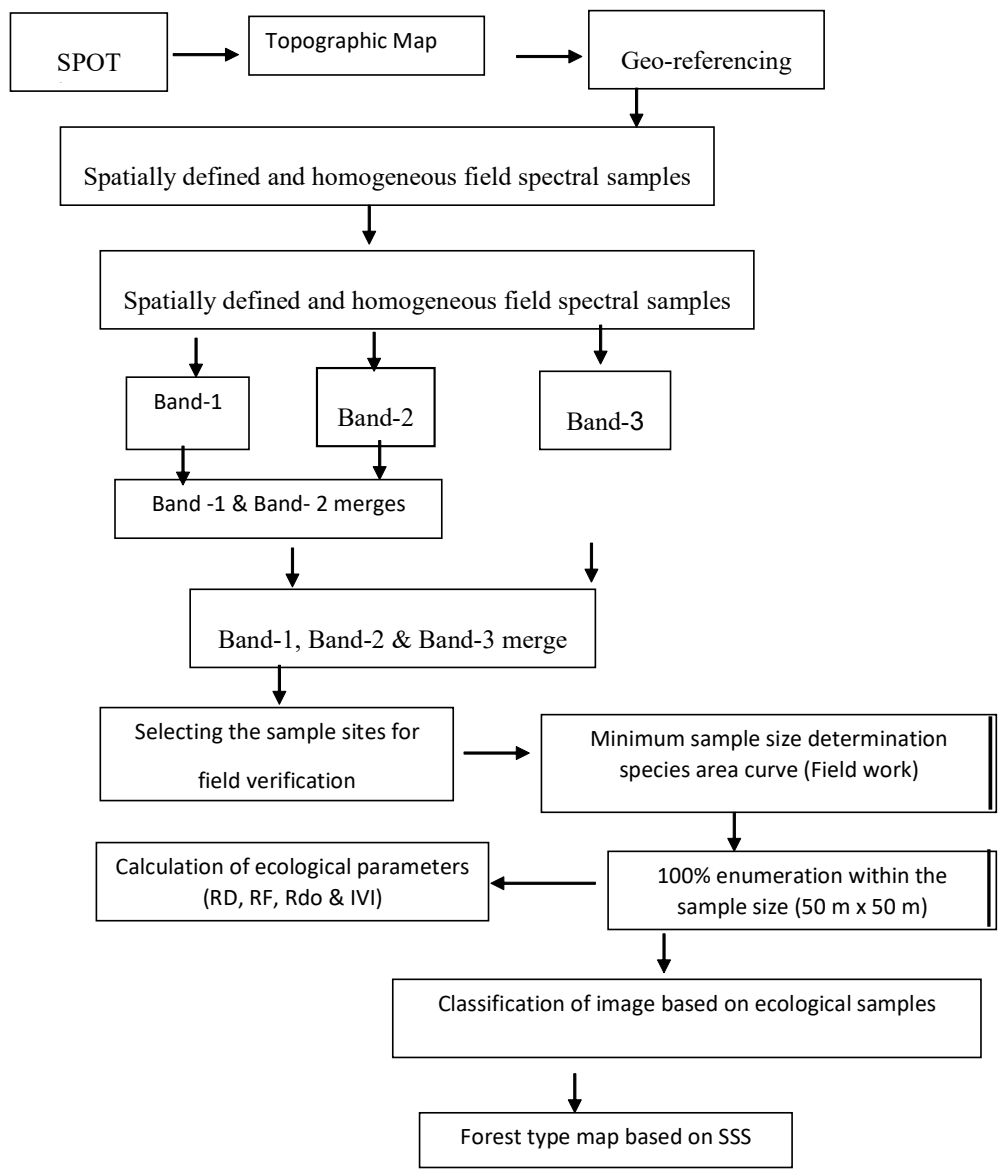

Figure 1. The flow chart for the entire work on the spatial distribution of Pinus roxburghii forest in the study area.

of Nepal. During the image processing following bands spatially defined and spectrally homogenous field samples have been shown in the map as in different colors.

\section{GREEN BAND (BAND 1):}

In the SPOT data of Green Band (Band 1) the minimum data file value is 23 and maximum data file is 72 . The data file values are grouped according to the following spectral ranges 23 to 27 (1); 28 to 32 (2); 33 to 37 (3); 38 to 42 (4); 43 to 47 (5); 48 to 52 (6); 53 to 57 (7); 58 to $62(8) ; 63$ to $67(9)$; and 68 to $72(10)$.

\section{RED BAND (BAND 2):}

For the Red Band (Band 2), minimum spectral value is 12 and maximum spectral value is 76 . Pixels were grouped as spectral class according to the following spectral range 12 to $16(1)$; 17 to 21 (2); 22 to $26(3) ; 27$ to 31 (4); 32 to $36(5) ; 37$ to 41 (6); 42 to $46(7) ; 47$ to $51(8) ; 52$ to $56(9) ; 57$ to $61(10) ; 62$ to $66(11) ; 67$ to $71(12)$; and 72 to $76(13)$.

\section{NIR BAND (BAND 3):}

For the NIR Band (Band 3), minimum spectral value is 14 and maximum spectral value is 93. Pixels were group as following spectral ranges, 14 to 18 (1); 19-23 (2); 24 to 28 (3); 29 
56 Spatial distribution of Pinus roxburghii in Rasuwa district of Nepal

to 33 (4); 34 to 38 (5); 39 to 43 (6); 44 to 48 (7); 49 to 53 (8); 54 to 58 (9); 59 to 63 (10); 64 to 68 (11); 69 to 73 (12); 74 to 78 (13); 79 to 83 (14); 84 to 88 (15) and 89 to 93 (16). The result of the analysis of the SPOT satellite imagery has been carried out using visual image processing techniques by the Mountain Environment and Natural Resources' System (MENRIS) Division of the International Centre for Integrated Mountain Development (ICIMOD), Nepal. Black and white Aerial photographs have been used as secondary data. Erdas Imagine 8.3.1 software was applied during the image processing or supervises classification.

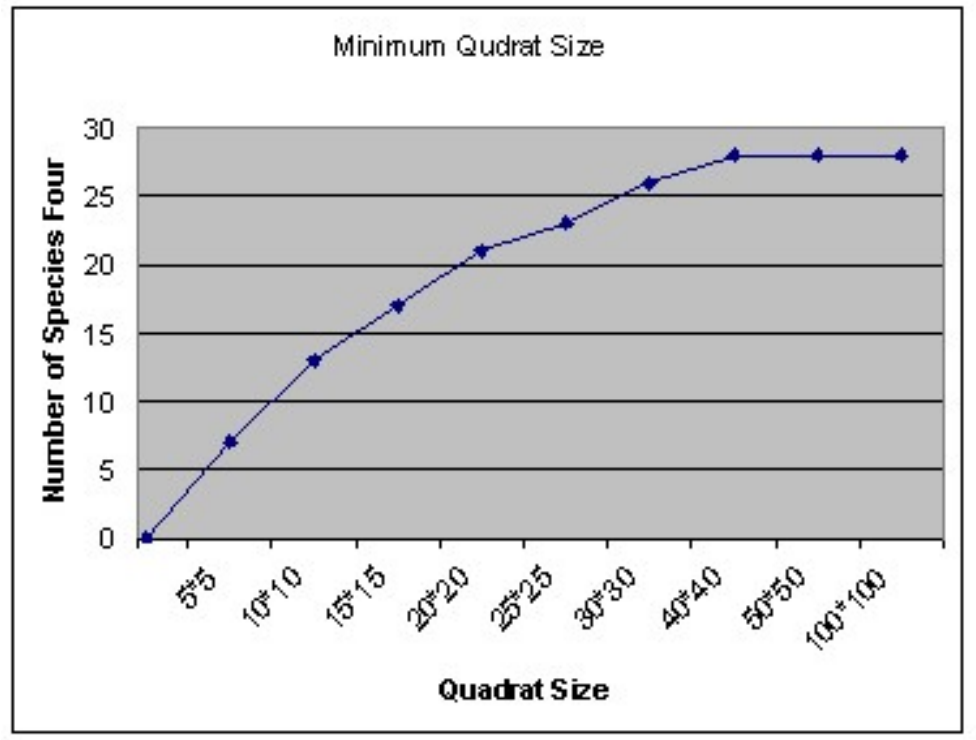

Figure 2. Graph plot of Minimum Quadrat size

\section{RESULTS AND DISCUSSIONS}

During ground truthing, homogeneous Pinus roxburghii forest was identified in 72 to 76 as one spectral class in Thanbochet lies in $85^{\circ} 17.58^{\prime} \mathrm{E}$ and $28^{\circ} 10.62^{\prime} \mathrm{N}$ at an altitude $1900 \mathrm{~m}$. 59 to 63 as one spectral class, which was identified as Pinus roxburghii forest in Lokyul lies in $85^{\circ} 14.12^{\prime} \mathrm{E}$ and $28^{\circ} 00.83^{\prime} \mathrm{N}$ at an altitude $2400 \mathrm{~m}$. Other associated trees and shrubs are Abies spectabilis (D.Don) Mirb. Berberis aristata DC., Eurya acuminata DC., Ilex dipyrena Wall., Lindera pulcherrima (Nees) Hook.f., Pieris formosa (Wall.) D.Don, Pyrus pashia Buch.-Ham. ex D.Don, Quercus incana Bartram Quercus lanata Sm., Quercus semecarpifolia Sm., Rhododendron arboreum Sm., Semecarpus anacardium L.f., Tsuga dumosa (D. Don) Eichler, and Viburnum cylindricum Buch.-Ham. ex D. Don.

The spectral range, 49 to 53 in the near infrared band discriminated Pinus roxburghii, lies in the Brabal jungle of Dhunche city near the main road located at $85^{\circ} 17.34^{\prime} \mathrm{E}$ and $28^{\circ} 06.6^{\prime} \mathrm{N}$ at an altitude $1950 \mathrm{~m}$. The associated trees are Cornus capitata Wall. and Rhododendron arboreum Sm., Berberis aristata DC., Indigofera dosua Buch-Ham. ex D.Don, Lyonia ovalifolia (Wall.) Drude, Pinus wallichiana A.B.Jacks., Prunus cerasoides Buch.-Ham. ex D.Don, Pyrus pashia Buch.-Ham. ex D.Don, Symplocos lucida (Thunb.) Siebold \& Zucc. Quercus incana Bartram, Quercus lanata Sm., Brucea javanica (L.) Merr. Semecarpus anacardium L.f., Schima wallichii Choisy, Tsuga dumosa (D.Don) Eichler. 
57 to 61 as one spectral class, which was identified as Pinus roxburghii forest is situated at the Barkhu locality near to Bremdang River. It lies in $85^{\circ} 17.00^{\prime} \mathrm{E}$ and $28^{\circ} 10.55^{\prime} \mathrm{N}$ at an altitude $2100 \mathrm{~m}$. It has the slope of $36.86^{\circ}$. The associated species are Pinus wallichiana A.B. Jacks. Alnus nepalensis D.Don, Cornus capitata Wall., Betula utilis D.Don, Lyonia ovalifolia (Wall.) Drude, Pyrus pashia Buch.-Ham. ex D. Don, Rhododendron arboreum Sm., Viburnum coriaceum Blume .

In Band 2, 63 to 67 as one spectral class discriminated Pinus roxburghii with Lyonia ovalifolia. The location is Bansbhanjyang lies in $85^{\circ} 15.56^{\prime}$ and $28^{\circ} 00.34^{\prime}$ at an altitude 1400 m. Other associated species are Alnus nepalensis D.Don, Berberis aristata DC., Careya arborea Roxb., Castanopsis indica (Roxb. ex Lindl.) A.DC., Engelhardtia spicata Leschen. ex Blume, Eurya cerasifolia (D.Don) Kobuski, Ficus semicordata Buch.-Ham. ex Sm., Osyris lanceolata Hochst. \& Steud., Pyrus pashia Buch-Ham. ex D.Don, Rhododendron arboreum Sm., Brucea javanica (L.) Merr. Schima wallichii Choisy, Shorea robusta Gaertn.f., Syzygium cumini (L.) Skeels, Viburnum coriaceum Blume, Woodfordia fruticosa (L.) Kurz .

\section{Acknowledgements}

I am indebted to Patan Muliple Campus of Tribhuvan University, International Centre for Integrated Mountain Development (ICIMOD), Department of National Parks and Wildlife Conservation, Govt. of Nepal, for providing me necessary help to do this work.

\section{LITERATURE CITED}

Archibald, P.D. 1987. GIS and Remote Sensing Data Integration, Geocarto International, Vol 3, pp.67-73.

Lillesand, T.M. \& Kieffer, R.W. 1979. Remote Sensing and Image Interpretation, Canada.

Manandhar, N.P. 2002. Plants and People of Nepal. Timber press, Inc. Portland, Oregon, USA.

Myint, M. 1996. The Use of remote sensing data for inventory on biodiversity of National Parks: A case study of the Alaungdaw Kathapa National Park in Myanma. A $\mathrm{Ph} . \mathrm{D}$. dissertation report, Asian Institute of Technology, School of Environment, Resource and development, Bangkok, Thailand.

Press, J.R.; Shrestha, K.K. \& Sutton, D.A. 2000. An Annotated Checklist of Flowering Plants of Nepal. British Museum (Natural History) London and Central Department of Botany, Tribhuban University. Kirtipur, Nepal.

Shrestha, I. 2016. Study on distribution of Rhododendron arboretum Sm. in Langtang National Park using Geographic Information System and Remote Sensing. Tribhuvan Univ. J., Center for Research Tribhuvan University, Kathmandu, Nepal. 29(1): $79-84$.

Shrestha, I. 2017. Detection of Lithocarpus gandifolius (DC.) S.N.Biswas Forest in Rasuwa District Usng Remote Sensing and Geographic Information System. Intn. J. Sci. Engg. Appl. Sci. 3(6): 145 - 150. 